Phonetica 1986;43:1-5

\title{
Contents, Vol. 43, No. 1-3, 1986
}

\section{Contents}

Preface 7

Modelling French Micromelody: Analysis and Synthesis

Di Cristo, A.; Hirst, D.J 11

Perceptual Compensation for Segmentally Conditioned Fundamental

Frequency Perturbation

Reinholt Petersen, N 31

F0 in the Production and Perception of Breathy Stops: Evidence from Hindi

Schiefer, L 43

Prosodic Effects on Lenis/Fortis Perception: Preplosive F0 and LPC Synthesis

Kohler, K.J.; Dommelen, W. A. van 70

F0 Segmental Cues Depend on Intonation: The Case of the Rise after Voiced Stops

Silverman, K 76

Interaction of Vowel F0 and Prosody

Steele, S.A 92

Speaking Rate and Segments: A Look at the Relation between Speech Production

and Speech Perception for the Voicing Contrast

Miller, J.L.; Green, K.P.; Reeves, A 106

The Perception of Quantity in Icelandic

Pind, J 116

A Search for Durational Rules in a Real-Speech Data Base

Carlson, R.; Granström, B 140 Editorial

With this issue, Phonetica continues its thematic publications, which, at irregular intervals, bring together invited papers for a comprehensive discussion of a topic of great interest in present-day basic phonetic research. As on two previous occasions, in 1981 and 1982, the aim was to unite a representative cross-section of phonetic centres, scholars and research questions in the contributions to a selected subject area. Not everyone I approached had the time to provide a paper or was able to meet the deadline, and there are no doubt scholars that were left out because I did not know of their work relevant to the topic. It is to be hoped that those who were contacted but had to decline, as well as those who were not contacted but could have contributed pertinent articles, are inspired by this volume to pursue the discussion in future fascicles of Phonetica. After all, the field is so broad that it cannot be treated exhaustively in a single publication. The purpose of these special issues within our Journal is to provide an overview of current activities in 'hot' research areas under a unifying theme, and to do so quickly. Thus again less than a year has elapsed between the sending out of my circular letter inviting scholars to submit papers and the distribution of this printed volume. Speed is an important consideration in the publication of the latest research results, for scientific journals as well as their contributors. But speed cannot be forced at the expense of quality. Since for the compilation of special issues only experts in the respective fields are approached, 
there is a pretty good guarantee that their papers can be accepted without substantial revision, although -even then - reviewers might have added some suggestions for improvement. As regards ordinary submissions, Phonetica has, for a long time, followed the rigid principle of having them reviewed by two referees. This, naturally, can delay publication quite considerably. In order to reduce this delay to a minimum we have worked out a new scheme by creating the position of Editor for North America. In very many cases in the past, papers were sent in by scholars from the United States whose subject-matter necessitated reviews from colleagues in North America. This meant that the manuscripts had to cross the Atlantic several times, especially when changes were necessary and the reviewers had to be consulted again. In these cases, a delay of several months was inevitable. From now on, authors from North America can send their papers directly to the North American Editor, who will arrange the reviewing process and will pass on the final revised version to me for the printing preparations in cooperation with the publisher. This way we hope to speed up publication to the benefit of au-

Editorial

thors and readers. I am most grateful to John Ohala for having taken on this office of Editor for North America and would ask prospective contributors from North America to send their manuscripts to him at the address given on the title page. This arrangement takes effect immediately.

At the same time, the editorial board has been reshaped by having more countries and research centres represented and by replacing existing members. Since it is the duty of board members to review papers from their fields and countries and to solicit good contributions from their research environment for publication in Phonetica this reshaping process will be continued in the interest of the advancement of our subject.

K.J.Kohler 